Session 2756

\title{
Digital Imaging for Engineering Students
}

\author{
Kauser Jahan, John Chen, Shreekanth Mandayam, Robert Krchnavek, Beena Sukumaran, \\ Yusuf Mehta, Jennifer Kadlowec, Parin von Lockette and Robi Polikar \\ Rowan University, College of Engineering \\ Glassboro, NJ 08028
}

\begin{abstract}
A multidisciplinary team of engineering faculty members at Rowan University are integrating digital imaging technology (DIT) into their undergraduate engineering curriculum. This exciting effort is based upon the experience and interest of faculty to promote new topics and innovative methods of teaching. The work is an effort to provide students with digital imaging experiences that make them ready for the marketplace. Projects involve the development of digital imaging experiements and curriculum and also the creation of a leading edge digital imaging laboratory/studio. This studio will facilitate the use of nontraditional learning approaches that encourage interactive learning, team building, and creative problem solving among students and instructors. A number of hands-on visual experiments are being developed and used to introduce students to the multidisciplinary engineering principles and use of DIT. Activities have also been developed for K-12 outreach.
\end{abstract}

\section{Introduction}

Digital Imaging Technology has advanced with great speed over the past few years inundating the consumer market, and has proven to be quite a valuable tool in the fields of science and engineering. Digital imaging technology can be found in electronic items common to the household such as digital cameras, computer scanners, and high definition television. It has proven a valuable tool in the medical field with devices like X-ray machines, magnetic resonance imaging machines and mammography machines. The technology has expanded to fields such as the food industry, pipeline industry, and structural and material analysis. Even though DIT has experienced wide spread use, the technology has yet to be used and introduced into formal education, both early, and undergraduate education. It represents one of the major research and development focus areas of the electrical industry today, with sales exceeding 10 billion dollars per year.

A digital image can be an enormous value for engineers and scientists. The topographic features of the earth, the severity of air, land and water pollution and the microstructure of materials are 
just some common examples where DIT is of tremendous significance. DIT technologies such as $\mathrm{X}$-ray tomography, optical or infrared imaging provides extensively detailed information that is invisible to the human eye thereby enhancing the understanding of the material or the process. Engineers play an important role in the development of this exciting field, yet undergraduate engineering students in civil and environmental, chemical and mechanical are not exposed to digital imaging through their coursework. This educational project is an effort by a multidisciplinary team of engineering faculty at Rowan University to integrate digital imaging technology (DIT) in their undergraduate engineering curriculum.

Traditionally courses related to digital image processing reside in the Physics and Electrical Engineering disciplines. However with the popularity in the use of digital imaging in various engineering applications there is a dire need for all engineers to be familiar with digital imaging fundamentals and applications. Educators are being challenged to develop teaching tools that engage students' imaginations and provide a platform for integrating state-of-the-art modern technology into the undergraduate curricula.

\section{Objectives}

The specific goals of this project are to:

- Provide specialized skills and training to students in the emerging field of digital imaging technology,

- Demonstrate the application of various imaging techniques in the characterization and visualization of the microstructure of different engineering materials,

- Expose students to the state of the art technologies in image acquisition, processing and analyses,

- Develop novel hands-on experiments using various imaging techniques that can be readily used by different engineering disciplines ,

- Ensure the highest quality SMET education by improving existing undergraduate courses, curricula and laboratories by developing hands-on innovative experiments,

- Dissemination of information through web pages, CD-ROMs and seminars for targeted audiences such as K-12 outreach, new faculty preparation and teacher/technician training.

To accomplish these goals, eight experiments using digital imaging techniques were proposed. These hands-on activities maximize the curricular impact by vertically integrating proposed DIT modules beginning with the Freshman year, followed by the fundamental engineering courses, the Junior-Senior research projects course, and finally, advanced level elective courses on DIT topics.

Some of the experiments have already been developed by Rowan faculty from funded research. The proposed modules are indicated in Table 1. 
Table 1: Proposed Digital Imaging Experiments

\begin{tabular}{|c|c|}
\hline \# & Proposed Experiments \\
\hline 1 & $\begin{array}{l}\text { Visualizing Pollutant Diffusion and Determining Pollutant Diffusion Speed from } \\
\text { Analyzing Sequential Images }\end{array}$ \\
\hline 2 & Imaging of Pore Spaces in Attached-Growth Biological Systems \\
\hline 3 & $\begin{array}{l}\text { Analysis of Internal Structure of Composite Materials and Prediction of } \\
\text { Performance }\end{array}$ \\
\hline 4 & Digital Imaging in Biomechanics \\
\hline 5 & Biomedical Image Processing Applications \\
\hline 6 & Ultrasonic Imaging System for Detecting Cracks in Metal and Concrete Pipes \\
\hline 7 & Image Compression using Multi-resolution Wavelet \\
\hline 8 & Applications of Thermal Imaging for Analysis \\
\hline
\end{tabular}

\section{Project Implementation}

A well-qualified diverse multidisciplinary team with the requisite expertise are participating in this project. All faculty are well established as both exceptional teachers and scholars. Furthermore, they have experience relevant to successfully develop and implement the proposed DIT experiences for the undergraduates. Each experiment is being developed by offering a Junior/Senior Engineering Clinic on Digital Imaging.

Rowan University has pioneered an innovative progressive engineering program that uses multidisciplinary team oriented teaching and learning ${ }^{1-6}$. The Rowan Engineering programs are include a 20-credit hour, 8-semester Engineering Clinic sequence. These Clinic classes our the Program's hallmark. Designed to be strongly multidisciplinary and project-focused, Engineering Clinics foster the structured development of engineering problem solvers. In the junior and senior year, clinics involve students in research/design or laboratory/product development activities. Many of these projects require various DIT techniques ${ }^{7-10}$. Experiments are being developed in the junior and senior clinics.

The DIT relevant topics and research typically reside in our Electrical Engineering core curriculum. However faculty have already teamed up from various disciplines to promote DIT in the curriculum. Upper level courses and multidisciplinary clinic projects have already been successfully implemented. Equipment holding for integrating DIT technology is also significant. The College has obtained microscopes, digital cameras, X-ray Scanners and various software for the project. Equipment acquisition has been completed and experiment development is in progress. A website is also being setup for rapid information dissemination. A module on digital imaging was offered for our middle school workshop for girls titled "Attracting Women into Engineering". Participants were introduced to basic concepts of digital imaging and were allowed to take digital images of a particular object and analyze the images. Digitizing of 
mamaograms and the identification of radiodense tissue through imaging was also introduced to the participants as a mechanism for detecting breast cancer.

\section{Conclusions}

This project allows Rowan engineering faculty and students to integrate and promote new technology into the engineering courses. The project also allows the development of digital imaging curriculum and focuses on the creation of a leading edge digital imaging laboratory/studio to facilitate the use of nontraditional learning approaches that encourage interactive learning, team building, and creative problem solving among students and instructors. It is anticipated that the developed modules will be easily adopted by other institutions and readily integrated in traditional engineering courses.

\section{Acknowledgement}

This project is being funded by a grant from the National Science Foundatio (NSF DUE \#0231033) and Rowan University. We would like to offer our sincere appreciation to the engineering clinic students at the College of Engineering for their support in developing the experiments.

\section{References}

1. Marchese, A. J., Constans, E., Dahm, K., Hollar, K., Hutto, D., Johnson, F., Sun, C. von Lockette, P., Kadlowec, J., Cleary, D., and Sukumaran, B. (2001). The Sophomore Engineering Clinic I: Integrating Statics, Solid Mechanics and Product Development in a Sophomore Level Design Course. ASEE Annual Meeting, Albuquerque, NM.

2. Johnson, F. S., Hutto, D., Dahm, K., Marchese, A. J., Sun, C., Constans, E., Hollar, K. and von Lockette, P. (2001). An Investigation into Interdisciplinary Team Teaching in Writing and Engineering: A Multi-Year Study. ASEE Annual Meeting, Albuquerque, NM.

3. Jahan, K. and R.A.Dusseau (1998) Environmental Design for Multidisciplinary Teams, Proceedings of the 1998 Annual Conference of ASEE, Seattle, Washington, June 28-July 1.

4. Jahan, K. et al., (1997d) The Rowan engineering program: Preparing Students for the Future Marketplace, Zone I Fall ASEE Conference, Wilmington, De, Oct. 1997.

5. Newell, J. A., Marchese, A. J, Ramachandran, R. P., Sukumaran, B. and Harvey, R. (1999). Multidisciplinary Design and Communication: A Pedagogical Vision. International Journal of Engineering Education. Vol 15, No. 5, pp. 376-382.

6. Schmalzel, J.L., A.J. Marchese, J. Mariappan, and S. Mandayam, "The engineering clinic: A four-year design sequence," $2^{\text {nd }}$ An. Conf. of Nat. Collegiate Invention and Innovation Alliance, Washington, D.C., March 13-15, 1998.

7. J. Neyhart, M. Kirlakovsky, L. Coleman, R. Polikar, M. Tseng and S. Mandayam,

"Automated Segmentation and Quantitative Characterization of Radiodense Tissue in Digitized 
Mammograms," Proceedings of the 28th Annual Review in Progress of Quantitative NDE, Brunswick, ME, USA, Aug. 2001.

8. Neyhart, M. Ciocco, R. Polikar, M. Tseng and S. Mandayam, "Dynamic Segmentation of Breast Tissue in Digitized Mammograms using the Discrete Wavelet Transform," Proc. of the 23rd Annual International Conference of the IEEE Engineering in Medicine and Biology Society, Istanbul, Turkey, Oct. 2001.

9. S. Mandayam, J. L. Schmalzel and A. J. Marchese, "Nondestructive evaluation of aircraft skin: Product design and development in the sophomore engineering clinic," Proceedings of the Frontiers in Education Conference, Phoenix, 1998.

10. S. Mandayam, K. Jahan and D. B. Cleary, "Ultrasonic based defect characterization in wastewater concrete pipelines using invariance transformation techniques," Proceedings of the 73rd Annual Conference and Exposition on Water Quality and Wastewater Treatment (WEFTEC), Anaheim, CA, October 14-18, 2000.

\section{Biography}

Dr. Kauser Jahan is an Associate Professor of Civil and Environmental Engineering at Rowan University, Glassboro, New Jersey. She completed her Ph.D. studies in the Department of Civil and Environmental Engineering at the University of Minnesota, Minneapolis in 1993. Dr. Jahan is a registered Professional Civil Engineer in Nevada and is actively involved in environmental engineering education and outreach for women in engineering. Her research interests include biodegradation of petroleum compounds and surfactant enhanced remediation of slightly soluble organic compounds.

Dr. Shreekanth Manadayam's research expertise is in digital signal and image processing and electromagnetic nondestructive evaluation. He has been extensively involved in the design and development of nondestructive evaluation systems, both as part of his graduate work and as a faculty member at Rowan University. He has established a thriving NDE laboratory at Rowan along with Drs. Jahan and Chen with sponsorship from NSF, US Army TACOM and the Water Environment Research Foundation. His present research interests lie in the area of medical image processing.

Dr. Robert Krchnavek's research interests are in the areas of nanotechnology, MEMS, photonics, electromagnetics, and materials processing. He has received funding from NSF, DOD, and numerous industrial sponsors. His teaching interests are in the areas of electromagnetics, wireless communications, fiber optics, and electronics. He currently is responsible for the purchase and maintenance of the FEVP-SEM being acquired through the New Jersey Commission on Higher Education-High Tech Workforce Grant.

Dr. Paris R. von Lockette is an Assistant Professor in Mechanical Engineering at Rowan University. He received his Ph.D. from University of Michigan at Ann Arbor. Dr. von Lockette's primary work focuses on uncovering the relationships between the microstructure of elastomers and polymers and their microscopic behavior. Dr. von Lockette's forte is the construction of computational simulations of the gelation (network formation) process in macromolecular materials. He also constructs constitutive and optical models to predict material behavior.

Dr. Jennifer Kadlowec's research interests include experimental investigation and modeling of mechanical behavior of materials, particularly rate and temperature dependence in elastomers and biotissues. She has published and presented work on experimental studies and modeling of radial-torsional coupling in elastomer bushings.

Dr. Beena Sukumaran is an Associate Professor of Civil and Environmental Engineering at Rowan University, Glassboro, New Jersey. She obtained her Ph.D. from Purdue University in the School of Civil Engineering with 
particular emphasis in Geotechnical Engineering. Her research interests include evaluating the performance of suction caissons in different soil conditions, effect of inherent particle characteristics on liquefaction potential, pavement analysis, fuzzy set applications in geotechnical engineering and use of the discrete element method to investigate the interaction forces acting on particles.

Dr. John Chen is an Associate Professor of Mechanical Engineering. He is active in the American Society for Engineering Education (ASEE) as an officer in the Educational Research and Methods Division and the Minorities in Engineering Division. Dr. John Chen's research interests lie in optical diagnostics of combustion phenomena and applications of heat transfer for nondestructive evaluation. He has experience with high-speed imaging combustion of coal and polymer particles for studying the physics and chemistry of combustion. More recently, his interest has shifted to applying thermal (infrared) imaging for detecting material defects, measuring material properties, and controlling process parameters during manufacturing.

Dr. Yusuf Mehta is an Assistant Professor of Civil and Environmental Engineering. He has extensive experience in pavement materials characterization. Dr. Mehta has been involved with several projects with the Departments of Transportation in various states (Florida, New Jersey, Rhode Island, Wisconsin).

Dr. Robi Polikar is an Assistant Professor of Electrical and Computer Engineering. He is the recipient of an NSF Career Award in 2003. His research encompasses highly interdisciplinary areas, including biological signal and image processing, flaw identification for NDT, bioinstrumentation, electronic nose for odorant identification, wavelets, neural networks, and computational models of learning. His most recent work includes using wavelets analysis of for digital mammography images. 